\title{
Effects of a naturally occurring amino acid substitution in bovine PrP: a model for inherited prion disease in a natural host species
}

Catherine E. Vrentas ${ }^{1}$, Justin J. Greenlee ${ }^{1}$, Gregory H. Foster ${ }^{1}$, James West ${ }^{2}$, Marianna M. Jahnke², MarkT. Schmidt ${ }^{1}$ and Eric M. Nicholson ${ }^{1 *}$ (1)

\begin{abstract}
Objective: The most common hereditary prion disease is human Creutzfeldt-Jakob disease (CJD), associated with a mutation in the prion gene resulting in a glutamic acid to lysine substitution at position 200 (E200K) in the prion protein. Models of E200K CJD in transgenic mice have proven interesting but have limitations including inconsistencies in disease presentation, requirement for mixed species chimeric protein constructs, and the relatively short life span and time to disease onset in rodents. These factors limit research on the mechanism by which the mutation drives disease development. Therefore, our objective was to provide the first assessment of cattle carrying the homologous mutation, E211K, as a system for investigating longer-term disease mechanisms. The E211 K substitution was associated with a case of bovine spongiform encephalopathy from 2006.
\end{abstract}

Results: We assessed the molecular properties of bovine E211K prion protein, characterized the molecular genetics of a population of cattle E211 K carriers (offspring of the original EK 211 cow) in relation to findings in humans, and generated preliminary evidence that the impacts of copper-induced oxidative stress may be different in cattle as compared to observations in transgenic mouse models. The cattle E211 K system provides the opportunity for future analysis of physiological changes over time.

Keywords: Prion, CJD, Creutzfeldt-Jakob disease, E200K, E211K, Cattle, Bos taurus, BSE, PrP, PRNP

\section{Introduction \\ Background}

Prion diseases are fatal diseases of the nervous system associated with misfolding of the prion protein $\left(\mathrm{PrP}^{\mathrm{C}}\right)$ into a more protease-resistant conformation $\left(\mathrm{PrP}^{\mathrm{Sc}}\right)$. In humans, a subset of disease is derived from the inheritance of mutations in the prion gene (PRNP). The most common form of hereditary Creutzfeldt-Jakob disease (CJD) is caused by a mutation in the prion gene (PRNP) resulting in a glutamic acid to lysine substitution at

\footnotetext{
*Correspondence: eric.nicholson@ars.usda.gov

1 United States Department of Agriculture, Agricultural Research Service, National Animal Disease Center, Ames, IA, USA

Full list of author information is available at the end of the article
}

amino acid 200 (E200 K) [1-3]. However, the exact basis by which the E200K change leads to $\operatorname{PrP}^{\mathrm{Sc}}$ accumulation and/or disease is unknown. The E200K change only slightly affects conformational stability of human recombinant PrP [4]. It has been proposed that an increase in hydrophobic surface exposure in E200 K protein contributes to aggregation and cellular toxicity [5].

Studies of human E200K carriers suggest a role for factors beyond simply the presence of the primary PRNP mutation in modulating CJD progression. In the Libyan Jewish population, there is a large variation in age of symptom onset among carriers (40-80+) [6]. Rates of CJD penetrance also vary between populations, from 67 to $96 \%[7,8]$. Notably, expression of the wild-type allele was higher in the majority of healthy middle-aged E200K 
carriers in a Libyan population, with an E: $\mathrm{K}$ transcript ratio of 50:1 in some individuals, whereas CJD-affected E200K heterozygotes primarily exhibited equivalent ratios of expression [9].

Recent work in a mouse model of E200K prion disease in which transgenic mice (carrying chimeric human/ mouse PRNP) develop neurological disease and accumulate $\operatorname{PrP}^{\mathrm{Sc}}$ suggests that oxidative stress synergistically interacts with the E200K mutation to induce disease. The E200K mutation impairs copper binding and is associated with increased copper sensitivity in cultured E200K fibroblasts and acceleration of disease in E200K mice dosed with copper [10]. Oxidative damage induced by reactive oxygen species generated by free copper ions [11] may also interact with the susceptibility of E200K $\mathrm{PrP}^{\mathrm{C}}$ to be spontaneously oxidized at methionine residues [12]. Characteristics of other mouse models for inherited prion disease are reviewed in [13].

Until recently, no examples of naturally occurring, inherited prion disease were known to exist in nonhuman species. In 2006, a 10-year old crossbred (Bos indicus $\times$ Bos taurus) United States beef cow was diagnosed with H-type BSE. This animal possessed a non-synonymous polymorphism in $P R N P$, resulting in the change of amino acid 211 from glutamic acid to lysine (E211K) [14]. As E211 is homologous to the human E200 residue, this animal was proposed to represent the first example of a genetically-based TSE in livestock. A female offspring of this BSE case also carried the E211K mutation [15].

\section{Rationale}

In order to develop therapeutic strategies against inherited prion diseases, an understanding of specific mechanisms resulting in disease development over time is important. Due to the long-term nature of many environmental stressors such as accumulation of oxidative damage in tissues, an experimental system is needed that allows for pre-symptomatic investigation in a species that is a natural host of prion diseases and has a lifespan significantly longer than that of a laboratory mouse. Therefore, here, we provide an initial characterization of the first natural host experimental system for genetic prion disease: heterozygous carriers of the analogous mutation in cattle PrP, E211K. Specifically, we consider characteristics of $\mathrm{EK}_{211}$ cattle that are not currently exhibiting disease signs (2-4 years of age), as a means of understanding preclinical phenotypes that may contribute to disease pathology in mammals with the $200 \mathrm{~K} / 211 \mathrm{~K}$ mutation.

\section{Main text}

\section{Origin and propagation of E211K cattle herd}

The $\mathrm{EK}_{211}$ female offspring, a Bos indicus crossbred animal described in detail in [15], was used to produce a small herd of heterozygous cattle by superovulation and embryo transfer, which remains under observation at the USDA. $\mathrm{EK}_{211}$ animals were bred by artificial insemination to generate the first $\mathrm{KK}_{211}$ (homozygous mutant) calf in 2013. Sibling wild-type calves ( $E_{211}$ homozygotes) were produced and characterized in parallel.

In the E200K mouse model, mice carrying the mutant allele on either a wild-type or null PRNP background exhibited onset of terminal illness at approximately 7 months of age [16], about a quarter of the life span of mice with the C57BL/6 J background (Jackson Laboratories). The disease endpoint of the 2006 BSE case represents approximately half the maximum lifespan of beef cattle $(\approx 20$ years), consistent with humans who develop disease in middle/late middle age. None of the monitored $\mathrm{EK}_{211}$ cattle have yet exhibited neurological signs.

\section{Evaluation of E211K protein folding and stability}

In order to evaluate the properties of the bovine E211K protein as compared to the human E200K protein, we compared stability characteristics of wild-type (glutamic acid residue at position 211) bovine recombinant $\operatorname{PrP}^{\mathrm{C}}$ to E211K bovine recombinant $\operatorname{PrP}^{\mathrm{C}}$ (representing residues 25-241; see Additional file 1 for detailed methods). When loss of secondary structure upon melting was monitored by loss of circular dichroism signal at $222 \mathrm{~nm}$, the $\mathrm{T}_{\mathrm{m}}$ (temperature at the unfolding midpoint) of bovine E211K protein $\left(65.7 \pm 0.2{ }^{\circ} \mathrm{C}\right)$ was lower than that of the wild-type protein $\left(68.5 \pm 0.3^{\circ} \mathrm{C}\right.$; Fig. 1a), similar to previous findings for $\mathrm{N}$-terminally truncated versions of recombinant human E200K $\left(\mathrm{T}_{\mathrm{m}}=67.0 \pm 0.9^{\circ} \mathrm{C}\right)$ and wild-type $\left(\mathrm{T}_{\mathrm{m}}=70.2 \pm 0.1{ }^{\circ} \mathrm{C}\right)$ proteins [4]. Differences in $\Delta \mathrm{H}_{\mathrm{m}}$ (change in enthalpy upon unfolding determined at the midpoint of unfolding) between wild-type and $\mathrm{E} 211 \mathrm{~K}$ bovine $\mathrm{PrP}$ were unremarkable $\left(\Delta \mathrm{H}_{\mathrm{m}}\right.$ (wild-type $)=63.6 \pm 5 \mathrm{kcal} \mathrm{mol}^{-1} ; \Delta \mathrm{H}_{\mathrm{m}}$ $\left.(\mathrm{E} 211 \mathrm{~K})=66.3 \pm 2 \mathrm{kcal} \mathrm{mol}^{-1}\right)$.

Using guanidine hydrochloride $(\mathrm{GdnHCl})$ unfolding at $23{ }^{\circ} \mathrm{C}$, the $\Delta \mathrm{G}_{\mathrm{H} 2 \mathrm{O}}$ value of unfolding (measurement of the thermodynamic stability of the protein) for wild-type bovine protein was $5.0 \pm 0.2 \mathrm{kcal} \mathrm{mol}^{-1}(\mathrm{~m}$ value $=2.3$ $\left.\pm 0.1 \mathrm{kcal} \mathrm{mol}^{-1} \mathrm{M}^{-1} ;[\mathrm{D}]_{1 / 2}=2.2 \pm 0.1 \mathrm{M} \mathrm{GdnHCl}\right)$, within error of that determined for $\mathrm{E} 211 \mathrm{~K}$ bovine protein $\left(\Delta \mathrm{G}_{\mathrm{H} 2 \mathrm{O}}=4.9 \pm 0.1 \mathrm{kcal} \mathrm{mol}^{-1}\right.$, m value $=2.4 \pm 0.04 \mathrm{kc}$ $\mathrm{al} \mathrm{mol}^{-1} \mathrm{M}^{-1}$; $[\mathrm{D}]_{1 / 2}=2.1 \pm 0.01 \mathrm{M} \mathrm{GdnHCl}$ ) (Fig. 1b). Similarly, for human full-length recombinant protein, $\Delta \mathrm{G}_{\mathrm{H} 2 \mathrm{O}}$ values for wild-type and $\mathrm{E} 200 \mathrm{~K}$ proteins were not significantly different at $22{ }^{\circ} \mathrm{C}$ [17]. At $39{ }^{\circ} \mathrm{C}$ (cattle body temperature), we did observe higher stability of the wild-type $\left(\Delta \mathrm{G}_{\mathrm{H} 2 \mathrm{O}}=5.0 \pm 0.4 \mathrm{kcal} \mathrm{mol}^{-1} ; \mathrm{m}\right.$-value $=2.9$ $\left.\pm 0.2 \mathrm{kcal} \mathrm{mol}^{-1} \mathrm{M}^{-1} ;[\mathrm{D}]_{1 / 2}=1.7 \pm 0.1 \mathrm{M} \mathrm{GdnHCl}\right)$ as compared to E211K $\left(\Delta \mathrm{G}_{\mathrm{H} 2 \mathrm{O}}=3.9 \pm 0.1 \mathrm{kcal} \mathrm{mol}^{-1}\right.$; m-v alue $=2.6 \pm 0.1 \mathrm{kcal} \mathrm{mol}^{-1} \mathrm{M}^{-1},[\mathrm{D}]_{1 / 2}=1.6 \pm 0.03 \mathrm{M}$ 

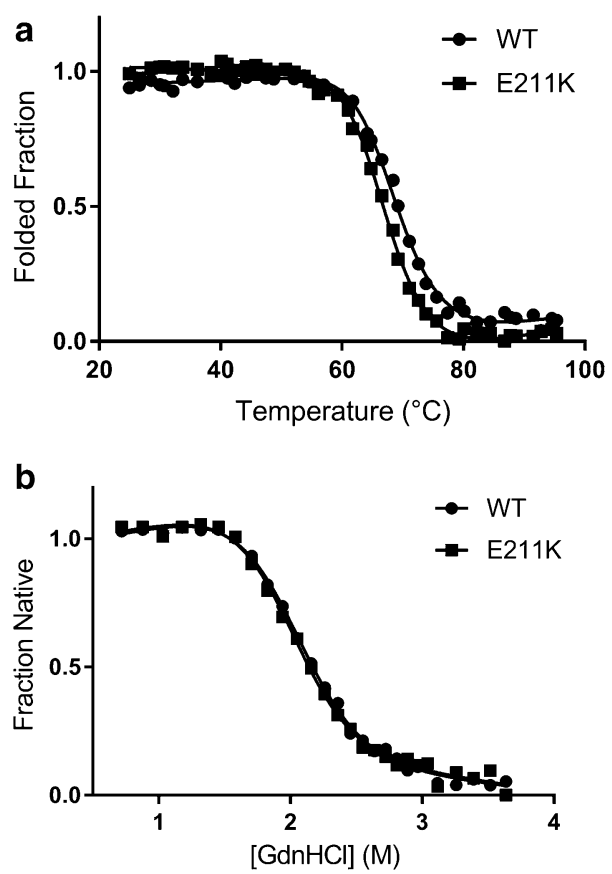

Fig. 1 Comparison of wild-type and E211K bovine prion protein properties. a Thermal denaturation of wild-type and E211K bovine recombinant prion proteins. $T_{m}$ results were consistent across multiple independent recombinant PrP preparations. Data points represent the results of a representative experiment (mean thermodynamic parameters for each mutant \pm standard deviation, across 4-7 replicate curves, are provided in the text). $95 \%$ confidence intervals for the $T_{m}$ were $68.3-68.7^{\circ} \mathrm{C}$ (wild-type) and $65.6-65.9^{\circ} \mathrm{C}$ (E211K). b $\mathrm{GdnHCl}$ denaturation of wild-type and $\mathrm{E} 211 \mathrm{~K}$ bovine recombinant prion proteins at $23^{\circ} \mathrm{C}$. A reduction in signal was noted between 0 and $0.6 \mathrm{M} \mathrm{GdnHCl}$, which we propose is due to disruption of aggregative interactions, due to the long unstructured $\mathrm{N}$-terminus on this version of the bovine PrPC protein in particular; however, an initial baseline was well-defined between 0.6 and $1.4 \mathrm{M} \mathrm{GdnHCl}$, which was used for the curve fitting. Mean thermodynamic parameters \pm standard deviation are provided in the text for each protein

GdnHCl) bovine prion protein. Overall, the relative properties of the bovine wild-type and mutant proteins are consistent with those of the human pair of proteins [4].

\section{Molecular genetics of $\mathrm{EK}_{211}$ cattle}

Previous findings suggested a role for gene regulation in modulating development of prion disease in E200K CJD [18]. Such a modulation in cattle could be regulated through a 23 base pair (bp) insertion/deletion (indel) polymorphism in the promoter region and a $12 \mathrm{bp}$ indel in exon 1 of PRNP. These sites have been implicated in BSE, where deletion at each site was over-represented in BSE cases as opposed to healthy animals, presumably by modulation of PRNP expression [19, 20]. We characterized the promoter region in $\mathrm{EK}_{211}$ animals via analysis of genomic DNA from the offspring of the U.S. 2006 case, which was heterozygous for both the $23 \mathrm{bp}$ and the $12 \mathrm{bp}$ indels. To identify the haplotype associated with $\mathrm{K}_{211}$, a single ovum was isolated from the offspring, and its genome was amplified. Sequencing of $P R N P$ revealed the ovum was $\mathrm{E}_{211}$, and sizes of PRNP PCR products indicated that DNA from the ovum carried insertions at both the 23 and $12 \mathrm{bp}$ indel sites. Therefore, the $K_{211}$ allele must be associated with the 23 and $12 \mathrm{bp}$ deletions. Upon birth of the first $\mathrm{KK}_{211}$ calf, its PRNP promoter was sequenced, confirming the haplotype of the $K_{211}$ allele to be deletions at both sites.

Next, we examined whether any of the heterozygous $E K_{211}$ cattle exhibited disparate levels of expression of the $\mathrm{E}$ and $\mathrm{K}$ alleles, as was observed in white blood cells of many middle-aged healthy human carriers [18]. One hypothesis is that an imbalance in allelic expression $(\mathrm{E}>\mathrm{K})$ earlier in the lifespan delays disease progression. Peripheral blood leukocytes (PBLs) were used as a noninvasive source of mRNA; this cell population has been demonstrated to express appreciable $\operatorname{PrP}^{\mathrm{C}}$ in cattle [21]. The E: $\mathrm{K}$ allelic ratio was determined by sequencing of PCR-amplified products from reverse-transcribed RNA pools from three $\mathrm{EK}_{211}$ cattle 4 years in age, utilizing allele quantification software (Additional file 1). The striking overexpression effect of the wild-type (E) allele in healthy human E200K carriers was not observed for any of these cattle samples (Table 1).

Healthy human E200K carriers also exhibit higher overall PRNP expression as compared to both $\mathrm{EE}_{200}$ individuals and affected $\mathrm{EK}_{200}$ individuals, leading to the suggestion that increased wild-type allele expression could have a protective effect [18]. To determine if these PRNP expression characteristics were also observed in $E_{211}$ heterozygous cattle, we measured the level of overall PRNP gene expression in each of three $\mathrm{EK}_{211}$ cattle (2-3 years of age) as compared to the level in each of three age-matched $\mathrm{EE}_{211}$ cattle. PBLs were again utilized as a non-invasive source of cells. The level of PRNP expression (relative to $A C T B ; \Delta C_{t}$ ) was only $5 \%$ higher in $\mathrm{EE}_{211}$ as compared to $\mathrm{EK}_{211}$ animals (Table 1; Additional file 2), consistent with very small differences in expression between the groups.

\section{Assessing oxidative stress in $\mathrm{EK}_{211}$ cattle}

Finally, we utilized our cattle herd to examine the proposal that mammals carrying the E200K/E211K mutation are subject to increased oxidative stress. Mutant mouse fibroblasts have an increased sensitivity to copper in cell culture [10]. Our qRT-PCR results demonstrate expression of PRNP RNA in PBLs, confirming previous work demonstrating that $P R N P$ expression in cattle PBLs is as high as that in fibroblasts [21]. PBLs isolated 
Table 1 Summary of characterization of properties of $\mathrm{EK}_{211}$ cattle

\begin{tabular}{|c|c|c|c|c|c|c|c|}
\hline 1 & 2 & 3 & 4 & 5 & 6 & 7 & 8 \\
\hline Calf number & Genotype & $\begin{array}{l}\% \text { WT Allele (G)/\% } \\
\text { K Allele (A) }\end{array}$ & $\begin{array}{l}\mathrm{C}_{\mathrm{t}} \\
(P R N P)\end{array}$ & $\begin{array}{l}\mathrm{C}_{\mathrm{t}} \\
(A C T B)\end{array}$ & $\Delta C_{t}$ & $\begin{array}{l}\text { Plasma TBARS: } \mathrm{OD}_{540} \\
\text { reading }\end{array}$ & $\begin{array}{l}\text { Plasma SOD } \\
\text { level (U/ml) }\end{array}$ \\
\hline \#79 & $\mathrm{EE}_{211}$ & - & 30.4 & 19.6 & 10.8 & 0.18 & 0.036 \\
\hline \#84 & $\mathrm{EK}_{211}$ & $54 / 46$ & 30.0 & 19.0 & 11.0 & 0.19 & 0.040 \\
\hline$\# 85$ & $\mathrm{EE}_{211}$ & - & 30.0 & 19.2 & 10.8 & 0.15 & 0.046 \\
\hline \#86 & $\mathrm{EE}_{211}$ & - & 30.9 & 20.3 & 10.6 & 0.20 & 0.046 \\
\hline \#87 & $\mathrm{EK}_{211}$ & $54 / 46$ & 30.0 & 18.9 & 11.2 & 0.20 & 0.055 \\
\hline \#88 & $\mathrm{EK}_{211}$ & $52 / 48$ & 30.6 & 18.9 & 11.6 & 0.17 & 0.054 \\
\hline $\mathrm{EE}_{211}$ Average & & & & & $10.8 \pm 0.1$ & $0.18 \pm 0.03$ & $0.043 \pm 0.007$ \\
\hline $\mathrm{EK}_{211}$ Average & & & & & $11.3 \pm 0.3$ & $0.19 \pm 0.02$ & $0.052 \pm 0.008$ \\
\hline
\end{tabular}

Column 3 presents the results of allele expression analysis of RNA from EK ${ }_{211}$ cattle PBLs. Ratios were assessed by analysis of sequencing reactions of PCR amplicons of the region around codon 211 in PRNP CDNA, using QSVAnalyzer as described in additional methods (Additional file 1). Cattle were 48 months of age at the time of this analysis. Columns 4-6 represent the results of qRT-PCR analysis of PRNP expression levels in both $\mathrm{EE}_{211}$ and $\mathrm{EK}_{211}$ cattle PBLs, with Column $\mathbf{6}$ indicating the $\Delta C_{t}=C_{t}(P R N P)-C_{t}(A C T B)$. Column 7 depicts results of TBARS readings on peripheral blood plasma samples. TBARS numbers reflect the OD ${ }_{540}$ of the cattle plasma samples as measured by the TBARS Kit from Cayman Chemical; due to interference from a separate absorbance peak in these samples, values are reported here as absorbance at $540 \mathrm{~nm}$ as opposed to a quantitative value based on the standard curve. Column $\mathbf{8}$ depicts the results of SOD (Superoxide Dismutase) assays on peripheral blood plasma samples. SOD values are expressed in $\mathrm{U} / \mathrm{ml}$ as derived from a standard curve generated with the SOD Assay Kit from Cayman Chemical. For columns 4-8, animals were 26 months of age at the time of analysis, with the exception of animal \#79, which was 32 months at the time. The bottom two rows depict average values across biological replicates for parameters, expressed \pm the $95 \% \mathrm{Cl}$ (confidence interval) in each case. (We note that we assume a normal distribution to calculate the $\mathrm{Cl}_{\text {; }}$ due to the unique nature of this cattle population, a small number of EK ${ }_{211}$ animals are available for testing, precluding more in-depth examinations of normality). The SOD assay on peripheral blood plasma was also completed on the offspring of the U.S. 2006 H-type BSE case (level = 0.057), and this value was included in the $\mathrm{EK}_{211}$ cattle average (Column 8)

from $\mathrm{EK}_{211}$ and $\mathrm{EE}_{211}$ cattle were treated with copper concentrations (selected to correspond to the range in [10]), followed by measurement of cell viability by MTT assay. We did not observe a difference in copper toxicity, and by extension the level of metal-induced stress experienced, between genotypes (Fig. 2). The profile of copper sensitivity of cells from a $\mathrm{KK}_{211}$ calf was comparable to that for an $\mathrm{EE}_{211}$ calf tested in parallel (Fig. 2, inset), suggesting that the increased mutant copper sensitivity observed in humans is not recapitulated in this cattle system.

Finally, to determine if the E211K polymorphism is causing a detectable level of general oxidative stress in preclinical cattle, we analyzed peripheral blood samples for molecular markers of systemic oxidative stress. Levels of superoxide dismutase (SOD) in blood plasma were comparable between $\mathrm{EE}_{211}$ and $\mathrm{EK}_{211}$ catthe that were $2-3$ years of age (Table 1); a $20 \%$ increase was observed in the $\mathrm{EK}_{211}$ group, but this difference did not reach the level of statistical significance (Additional file 2). A colorimetric TBARS assay, which detects lipid peroxidation resulting from oxidative stress, was also performed on the plasma samples. No genotype-dependent differences were noted (Table 1). Therefore, while it is possible that signs of oxidative damage in the blood will increase over time, young, preclinical cattle heterozygotes do not exhibit large increases in blood markers of systemic oxidative stress (Additional file 2).

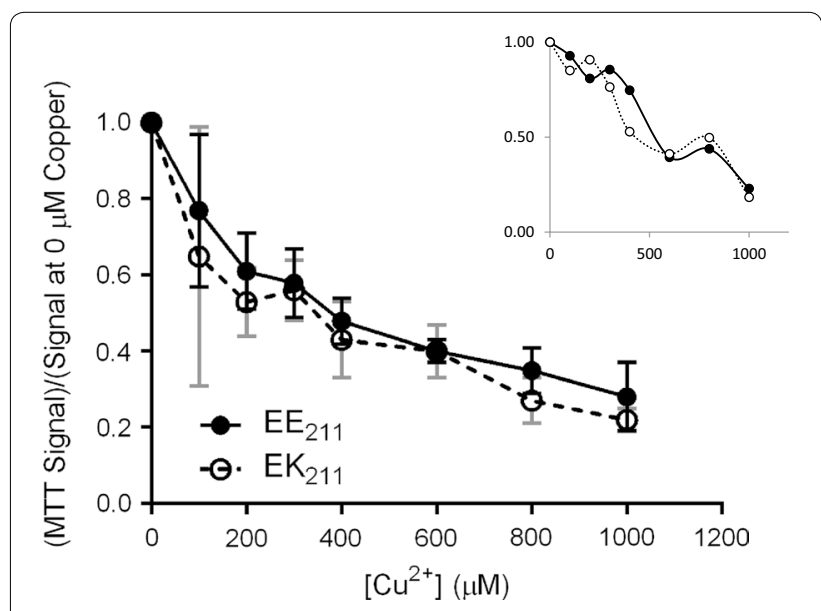

Fig. 2 Test of copper sensitivity in PBLs from wild-type and $\mathrm{EK}_{211}$ cattle. PBLs isolated from each calf were treated with increasing concentrations of $\mathrm{Cu}^{2+}$ for $48 \mathrm{~h}$, and cell viability was determined by the MTT assay. MTT values from triplicate wells for each animal were averaged, followed by averaging across genotypes to generate the displayed curves (the animals used were the same 6 as in Table 1, with the same bleed dates); data are displayed as the average MTT reading as a fraction of the average reading at $0 \mu \mathrm{MCu}^{2+}$, and the error bars represent the $95 \% \mathrm{Cl}$ for the calves of each genotype. Inset: Comparison of single $\mathrm{KK}_{211}$ calf (filled circles) to $\mathrm{EE}_{211}$ calf (open circles). Data analysis and axis labels are identical to the main panel

\section{Limitations}

This study describes the first natural host experimental system for genetic prion diseases, including molecular characterization of bovine E211K recombinant prion 
protein and molecular genetic experiments on $\mathrm{EK}_{211}$ cattle.

Limitations include the small sample size of these (rare) cattle, therefore limiting the ability to assess normality of parameters and limiting statistical power. However, in Additional file 2, we present t test comparisons and predictions of statistical power to provide information about the magnitude of differences in physiological parameters predicted to be detectable in further experiments with this herd. Additionally, unlike the case of the E200K prion mouse model (for which many PRNP-null mice exist), $P R N P$-null bovine cells were not available for comparative analysis.

Future characterization of the cattle over time, including analysis of parameters assessed in this study coupled with analysis of necropsied animals, will afford us the ability to assess molecular mechanisms of pathology. For example, brain tissue samples may reveal evidence of oxidative damage not perceivable in peripheral blood samples.

\section{Additional files}

Additional file 1. Additional methods. More detailed information about methodologies used to generate data in Fig. 1, Fig. 2, and Table 1, including primers, GRT-PCR amplification conditions, and cycling information, as well as information about cell assays and recombinant prion protein purification

Additional file 2. Additional Statistical Analysis. Additional description of statistical tests completed on the data, potential statistical limitations and their implications, and prospective statistical power analyses for assessment of effects of the 200K mutation.

\section{Abbreviations}

PRNP: prion gene; CJD: Creutzfeldt-Jakob disease; PrP: prion protei; $\mathrm{T}_{\mathrm{m}}$ : temperature at the unfolding midpoint; $\Delta H_{m}$ : change in enthalpy upon unfolding determined at the midpoint of unfolding; bp: base pair; PBLs: peripheral blood leukocytes; SOD: superoxide dismutase.

\section{Authors' contributions}

CEV designed the study, performed experiments, and prepared the manuscript; JJG contributed animal specimens for analysis, provided clinical information and interpretation, and helped draft the manuscript; GF designed and performed molecular genetics experiments; JKW and MMJ bred the experimental cattle population; MTS designed and performed recombinant protein experiments; and EMN conceived experiments and helped draft the manuscript. All authors read and approved the final manuscript.

\section{Authors' information}

Disclaimer: Mention of trade names or commercial products in this article is solely for the purpose of providing specific information and does not imply recommendation or endorsement by the U.S. Department of Agriculture. USDA is an equal opportunity employer.

\section{Author details}

${ }^{1}$ United States Department of Agriculture, Agricultural Research Service, National Animal Disease Center, Ames, IA, USA. ${ }^{2}$ Department of Veterinary Diagnostic and Production Animal Medicine, College of Veterinary Medicine, lowa State University, Ames, IA, USA.

\section{Acknowledgements}

We are grateful to Semakaleng Lebepe-Mazur, Andrew Gibson, Kevin Hassall, Leisa Mandell, and Trudy Tatum for their excellent technical contributions to the animal and laboratory experiments at the National Animal Disease Center, and to Dr. Marcus Kehrli for helpful technical discussions.

\section{Competing interests}

The authors declare that they have no competing interests.

\section{Availability of data and materials}

No applicable data. Relevant materials (e.g., primer information) is available upon request to the corresponding author.

\section{Consent for publication}

Not applicable.

\section{Ethics approval and consent to participate}

All animal experiments were carried out in accordance with the Guide for the Care and Use of Laboratory Animals (Institute of Laboratory Animal Resources, National Academy of Sciences, Washington, DC) and the Guide for the Care and Use of Agricultural Animals in Research and Teaching (Federation of Animal Science Societies, Champaign, IL) under the approval of the Institutional Animal Care and Use Committee of the National Animal Disease Center (protocol numbers 2415 and 2618).

\section{Funding}

This study was funded by intramural funding of the Agricultural Research Service, U.S. Department of Agriculture.

\section{Publisher's Note}

Springer Nature remains neutral with regard to jurisdictional claims in published maps and institutional affiliations.

Received: 20 October 2017 Accepted: 13 December 2017

Published online: 20 December 2017

\section{References}

1. Hsiao K, Meiner Z, Kahana E, Cass C, Kahana I, Avrahami D, et al. Mutation of the prion protein in Libyan Jews with Creutzfeldt-Jakob disease. N Engl J Med. 1991:324:1091-7.

2. D'Alessandro M, Petraroli R, Ladogana A, Pocchiari M. High incidence of Creutzfeldt-Jakob disease in rural Calabria, Italy. Lancet. 1998;352:1989-90.

3. Mitrova E, Belay G. Creutzfeldt-Jakob disease with E200K mutation in Slovakia: characterization and development. Acta Virol. 2002;46:31-9.

4. Swietnicki W, Petersen RB, Gambetti P, Surewicz WK. Familial mutations and the thermodynamic stability of the recombinant human prion protein. J Biol Chem. 1998:273:31048-52.

5. Corsaro A, Thellung S, Bucciarelli T, Scotti L, Chiovitti K, Villa V, et al. High hydrophobic amino acid exposure is responsible of the neurotoxic effects induced by E200K or D202N disease-related mutations of the human prion protein. Int J Biochem Cell Bio. 2011;43:372-82.

6. Chapman J, Ben-Israel J, Goldhammer Y, Korczyn AD. The risk of developing Creutzfeldt-Jakob disease in subjects with the PRNP gene codon 200 point mutation. Neurology. 1994;44:1683-6.

7. Ladogana A, Puopolo M, Poleggi A, Almonti S, Mellina V, et al. High incidence of genetic human transmissible spongiform encephalopathies in Italy. Neurology. 2005;64:1592-7.

8. Spudich S, Mastrianni JA, Wrensch M, Gabizon R, Meiner Z, Kahana I, et al. Complete penetrance of Creutzfeldt-Jakob disease in Libyan Jews carrying the E200K mutation in the prion protein gene. Mol Med. 1995:1:607-13.

9. Rosenmann R, Halimi M, Kahana I, Biran I, Gabizon R. Differential allelic expression of PrP mRNA in carriers of the E200K mutation. Neurology. 1997;49:851-6. 
10. Canello T, Friedman-Levi Y, Mizrahi M, Binyamin O, Cohen E, Frid K, et al. Copper is toxic to PrP-ablated mice and exacerbates disease in a mouse model of E200K genetic prion disease. Neurobiol Dis. 2012;45:1010-7.

11. Gaetke LM, Chow CK. Copper toxicity, oxidative stress, and antioxidant nutrients. Toxicology. 2003;189:147-63.

12. Canello T, Frid K, Gabizon R, Lisa S, Friedler A, Moskovitz J, et al. Oxidation of Helix-3 methionines precedes the formation of PK resistant PrP. PLoS Pathog. 2010;6:e1000977.

13. Watts JC, Prusiner SB. Experimental models of inherited PrP prion diseases. Cold Spring Harb Perspect Med. 2017;7(11). https://doi. org/10.1101/cshperspect.a027151.

14. Richt JA, Hall SM. BSE case associated with prion protein gene mutation. PLoS Pathog. 2008;4:e1000156.

15. Nicholson EM, Brunelle BW, Richt JA, Kehrli ME Jr, Greenlee J. Identification of a heritable polymorphism in bovine PRNP associated with genetic transmissible spongiform encephalopathy: evidence of heritable BSE. PLoS ONE. 2008;3:e2912.

16. Friedman-Levi Y, Mizrahi M, Frid K, Binyamin O, Gabizon R. PrP ${ }^{S T}$, a soluble, protease resistant and truncated PrP form features in the pathogenesis of a genetic prion disease. PLoS ONE. 2013;8:e69583.
17. Cereghetti GM, Schweiger A, Glockshuber R, Van Doorslaer S. Stability and $\mathrm{Cu}(\mathrm{II})$ binding of prion protein variants related to inherited human prion diseases. Biophys J. 2003;84:1985-97.

18. Rosenmann R, Halimi M, Kahana I, Biran I, Gabizon R. Differential allelic expression of PrP mRNA in carriers of the E200K mutation. Neurology. 1997:49:851-6.

19. Sander P, Hamann H, Drogemuller C, Kashkevich K, Schiebel K, Leeb T. Bovine prion protein gene (PRNP) promoter polymorphisms modulate PRNP expression and may be responsible for differences in bovine spongiform encephalopathy susceptibility. J Biol Chem. 2005:280:37408-14.

20. Juling K, Schwarzenbacher H, Williams JL, Fries R. A major genetic component of BSE susceptibility. BMC Biol. 2006:4:33.

21. Richt JA, Kasinathan P, Hamir AN, Sathiyaseelan T, Vargas F, Sathiyaseelan J, et al. Production of cattle lacking prion protein. Nat Biotechnol. 2007;25:132-8

\section{Submit your next manuscript to BioMed Central and we will help you at every step:}

- We accept pre-submission inquiries

- Our selector tool helps you to find the most relevant journal

- We provide round the clock customer support

- Convenient online submission

- Thorough peer review

- Inclusion in PubMed and all major indexing services

- Maximum visibility for your research

Submit your manuscript at www.biomedcentral.com/submit 